\title{
Bone morphogenetic proteins: multifunctional regulators of vertebrate development
}

\author{
Brigid L.M. Hogan \\ Howard Hughes Institute and Department of Cell Biology, Vanderbilt University Medical School, Nashville, Tennessee \\ 372.32-2175 USA
}

A recurrent theme in embryonic development and tissuc regeneration is that cells communicate with each other using just a handful of conserved families of signaling molecules. One of the largest of these multifunctional families is that of the bone morphogenetic proteins (BMPs), with $>20$ members identified in organisms ranging from sea urchin to mammals (Fig. 1). The name BMP was first given to three proteins purified from a demineralized bovine bone preparation that induced ectopic cartilage and endochondral bone when implanted in experimental animals (Wozney et al. 1988). One of these proteins (BMPl) was a putative protease of the astacin family, whereas the other two \{BMP2 and BMP3) were related to human transforming growth factor $\beta$ (TGF $\beta$ ). It is now clear that the name BMP is misleading because there is strong genetic and experimental evidence that these molecules regulate biological processes as diverse as cell proliferation, apoptosis, differentiation, cell-fate determination, and morphogenesis. Morcover, the vertebrate BMPs are involved in the development of nearly all organs and tissues, including the nervous system, somites, lung, kidney, skin, and gonads, as well as in critical steps in the establishment of the basic embryonic body plan.

This review focuses on recent studies related to BMP function in vertebrates, particularly those involving mutations of BMP-encoding genes in mice. Additional information about the larger TGF $\beta$ superfamily can be found in other reviews (Kingsley 1994a,b; McPherron and Lee 1996). The complexity of the numerous transmembrane serine-threonine kinases that act as BMP signaling receptors precludes full discussion here, but again, a number of excellent reviews are available, in addition to those cited above (Massague et al. 1994; Massague and Weis-Garcia 1996|

\section{Structure of BMPs}

Like all members of the TGF $\beta$ superfamily, BMPs are synthesized as large precursors, which are processed and proteolytically cleaved to yield carboxy-terminal mature protein dimers. BMPs are distinguished from other mem- bers of the family by having, in general, seven, rather than nine, conserved cysteines in the mature region. The crystal structures of two members of the TGFB superfamily have now been solved: TGFB2 (Daopin et al. 1992; Schlunegger and Grutter 1992) and BMP7/Op2 |Griffith et al. 1996]. In both, the core of the monomer structure is a cystine knot (McDonald and Hendrickson 19931 involving intramolecular bonding of six of the seven conserved cysteines; the seventh participates in intermolecular disulfide bonding. Extending from the monomer core in one direction are two finger-like projections made from antiparallel $\beta$ strands and, on the opposite side, an $\alpha$-helical loop. The overall monomer structure has thus been likened to an open hand with a pair of extended fingers, in which the cystine knot represents the palm and the helical loop, the heel. The subunits are aligned such that the fingers of one monomer rest in the heel of the other. In the case of BMP7, the dimer may interact with its receptor(s) through a patch of residues contributed by the tips of the fingers of one monomer and part of the heel of the other /Griffith et al. 19961. At least two members of the BMP family, Vgr2/ Gdf3 and Gdf9, lack the cysteine involved in intermolecular bonding, suggesting that covalent bonding is not essential for dimer formation.

\section{BMP processing and putative binding proteins}

Little is known about intracellular assembly, processing, and secretion of BMP proteins and their extracellular localization. In part, this lack of information has resulted from difficulties in obtaining specific, high-affinity antibodies, although some polyclonal and monoclonal antibodies are available (Wall et al. 1993; Gitelman 1994; Masuhara et al. 1995). All of the evidence suggests that dimerization and proteolytic cleavage between the proand mature region precede secretion. Amino-terminal sequencing of secreted protein is consistent with proteolytic cleavage occurring immediately carboxy-terminal to a dibasic RXXR site before the first cysteine of the mature region (see references in Ozkaynak et al. 1992). That dimerization occurs before cleavage is supported by 


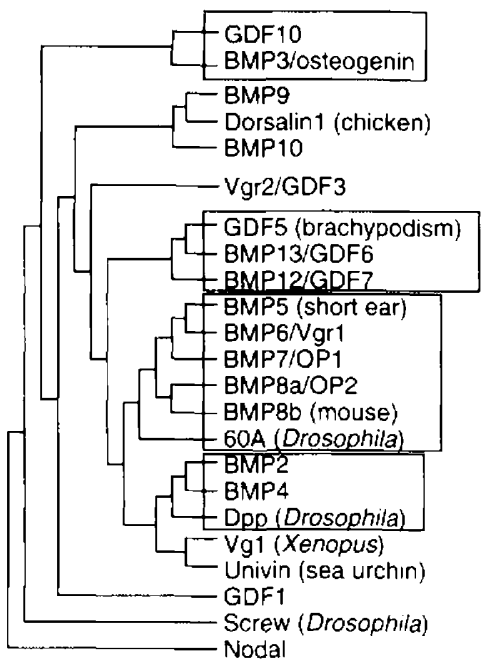

Figure 1. The BMP superfamily. Relationships between members are shown, determined on the basis of sequence comparisons of the carboxy-terminal mature region. In some cases, members clearly belong to subfamilies, and these are enclosed by boxes. However, the relationships between other members is somewhat arbitrary because their position on the tree varies depending on the algorithm used to calculate relationships. In $X e n o p u s$, three proteins have been identified that are related to mouse Nodal (XNr1, XNr2, and XNr3) (Jones et al. 1995; Smith et al. 1995). Also not shown are zebrafish Radar (Rissi et al. 1995) and Xenopus Admp (Moos et al. 1995). References for all other sequences can be found in Griffith et al. (1996). This figure was modified from one kindly provided by Drs $\mathrm{V}$. Rosen and $\mathrm{A}$. Celeste (Genetics Institute, Cambridge, MAI. Nomenclature used in this review follows that of $M$. Davisson (pers. comm.) for mouse genes. Much information on BMP gene expression in the mouse embryo is contained in the The Jackson Laboratory gene expression data base (http://www.informatics.jax.org/ gxd.htmll.

the finding that mutated polypeptides lacking the RXXR sequence can inhibit secretion of endogenous mature protein and thereby act as dominant-negative inhibitors of BMP function (Hawley et al. 1995). It is possible that intracellular endoproteases of the furin family, which process other propeptides at dibasic sites, are responsible for the proteolytic cleavage of BMPs, although no direct evidence is currently available (Barr 1991).

Extensive studies of TGF $\beta 1$ processing show that the protein is secreted as an inactive molecule in which the pro-region remains noncovalently complexed with the mature region, and that extracellular protcolytic cleavage is required to release the biologically active mature dimer from the pro-region. This process is complicated further by the fact that latent TGF $\beta$ can associate with a large, multidomain latency binding protein $|\mathrm{LBP}\rangle$ which binds collagen and fibronectin (Saharinen et al. 1996). LBP may thus provide a mechanism for sequestering inactive TGF $\beta$ in the extracellular matrix, so that its release can be precisely controlled. At present there is no direct evidence for latent forms of any BMP, or association with binding proteins homologous to LBP. How- ever, a number of other extracellular proteins probably bind BMPs in vivo and so limit their availability and domain of influence. Candidate binding proteins are Follistatin, known to bind activin and BMP7 (Nakamura et al. 1990; Yamashita et al. 19951, and extracellular matrix proteins with Follistatin-like domains (Timpl and Brown 1996). Evidence that the proteins Chordin and Noggin bind to or counteract BMPs in vivo will be discussed in detail below.

In Drosophila, the product of the tolloid gene, which encodes a putative protease of the astacin family, enhances Decapentaplegic (Dpp) function, possibly by cleaving an inactive Dpp protein complex (Shimell et al. 1991; Childs and O'Connor 1994; Finelli et al. 1994). One of the vertebrate proteins most closely related to Tolloid is BMP1, which encodes a protease that cleaves the carboxy-terminal peptide of procollagen and facilitates collagen assembly into fibers (Kessler et al. 1996). At present it is still possible that BMPl cleaves other extracellular proteins, in addition to procollagen, that might bind and sequester BMPs. Although mice homozygous for a null mutation in BmpI have defects in ventral body wall closure and do not survive beyond birth, they have no major skeletal abnormalities, suggesting functional redundancy between $B m p 1$ and related genes in collagen processing (N. Suzuki and B.L.M. Hogan, unpubl.\}.

It is still unclear whether the BMP pro-region has a specific intracellular function. This region may affect the rate and efficiency of dimer formation and processing. Some BMPs are readily processed and secreted from embryonic or transfected cells, whereas the secretion of others is very inefficient (Hazama et al. 1995). In addition, fusion of the pro-region of one BMP (e.g., BMP2) with the mature region of a poorly secreted family mem. ber [e.g., $\mathrm{Vgl}$ ) has been shown to enhance production of mature ligand (Dale et al. 1993; Thomsen and Melton 19931

\section{Homodimers and heterodimers}

Given the overlap in expression patterns of several of the genes encoding BMPs, a very important unanswered question is whether BMPs have specific functions as heterodimers in vivo. Heterodimers have been generated in vitro (Hazama et al. 1995) and, in the case of BMP2BMP7 and BMP4-BMP7, they are much more active than either homodimer (Hazama et al. 1995; Suzuki et al. 1996). However, although Bmp2, Bmp4, and Bmp7 expression domains overlap in many tissues, homozygous null mutants have very different phenotypes (see below), arguing indirectly against a unique role for heterodimers of these BMPs in vivo. Heterodimers might also act as competitive inhibitors of homodimers at the level of receptor binding, as proposed for the antagonistic effects of activin and inhibin (Xu et al. 1995).

\section{Do BMPs behave as morphogens in vertebrate embryogenesis?}

A morphogen is defined as a molecule distributed in a 
gradient that alters the developmental fatc of target cells in a concentration-dependent manner. In Drosophila there is substantial evidence that Dpp acts as a morphogen during dorsal-ventral patterning of the blastoderm stage embryo (Ferguson and Anderson 1992; Wharton ct al. 1993). The differential response of Xenopus ectoderm cells to different concentrations of activin provides evidence for its action as a morphogen during mesoderm patterning (Green et al. 1992; Gurdon et al. 1995), but whether activin, or any other TGF $\beta$ family member, really does so in vivo is still uncertain (Wilson and Melton 1994). Simple models of morphogen action assume that the ligand diffuses freely from a source, and there is evidence that exogenous activin can do this and establish a graded pattern of mesodermal cell types in Xeno. pus embryonic tissues (Gurdon et al. 1994). However, similar results have not yet been reported for BMPs. An alternative model is that a short-range BMP signal is progressively propagated from one cell to another across a field. In either model, signal reception could be modified locally by cell-cell communication mediated by other factors, or by competition or cooperation between related ligands at the level of receptor binding.

As discussed below, there is evidence that BMPs can either stimulate cell proliferation or promote cell differentiation and exit from the cell cycle, depending on the target cell type. This raises the interesting possibility that the same BMP could affect cells in different ways, depending on the concentration of ligand to which the cells are exposed; for example, low concentrations might stimulate cell proliferation, whereas higher concentrations might promote differentiation.

\section{Upstream regulation of BMPs}

In Drosophila, there is considerable understanding of the mechanisms underlying the regulation of $d p p$ expression. In the blastoderm embryo, for example, $d p p$ is repressed by Dorsal, a transcription factor related to NF-kB (Schwyter et al. 1995). In the midgut, $d p p$ is regulated positively and negatively by the homeo domain proteins, Ultrabithorax $(\mathrm{Ubx})$ and Abdominal-A $\mid \mathrm{Abd}-\mathrm{A})$, respectively, and DNA sequences required for direct activation by Ubx have been identified (Bienz 1994; Capovilla et al. 1994!. In imaginal discs, dpp expression is regulated by the segment polarity gene, hedgehog $\{h h\}$, which encodes a protein that generates, by autoproteolysis, a soluble 19-kD amino-terminal signaling peptide. Several components of the pathway between $\mathrm{Hh}$ and $d p p$ have been identified, although the precise details of how they interact are not yet known. Key genes are patched (ptc, encoding a multipass trans-membrane protein|, fused ( $f u$, encoding a putative serine-threonine kinase), costal-2 (cos-2, encoding a novel kinesin heavy chain-related protein), and cubitus interruptus ( $c i$, a zinc-finger transcription factor!. Another gene involved in regulation of $d p p$ by $\mathrm{Hh}$ is $p k a-C 1$, which cncodes a cAMP. dependent protein kinase catalytic subunit (Lepage et al. 1995; Pan and Rubin 1995; Strutt et al. 1995). pka-C1 appears to repress $d p p$, but it is unclear whether it does this through ptc-dependent or -independent pathways (for references and review, sce Forbes et al. 1993; Bonini and Choi 1995; Ingham 1995; Johnson et al. 1995; Sanchez-Herrero et al. 1996).

Although some gene regulatory circuits are surprisingly conserved during evolution, the existence of $>20$ BMPs in vertebrates, compared with 3 in Drosophila (the products of the dpp, screw, and $60 \mathrm{~A}$ genes/ cautions against sweeping generalizations for these signaling systems. Nevertheless, there are indications that parts of the Hh-dpp pathway identified in Drosophila also function in vertebrates. Three mammalian genes related to hh have been identified [Sonic hedgehog (Shh), Desert hedgehog $\{D h h\}$, and Indian hedgehog (Ihh)\}. As discussed below, transcripts are often found in the embryo in sites adiacent to those expressing BMP genes, and in the chick limb bud and hindgut ectopic Shh locally induces $B m p 2$ and $B m p 4$, respectively. Recently, a mouse homolog of ptc was characterized, and its transcripts localized in the embryo to many sites adjacent to those expressing Shh. Moreover, $p t c$ is up-regulated in the neural tube and chick limb bud in response to ectopic $S h h$ (Goodrich et al. 1996; Marigo et al. 1996). Three zincfinger protein-encoding mouse genes related to $c i \mid G l i$, Gli2, and Gli3) have been identified (Hui et al. 1994), and experiments are in progress in a number of laboratories testing for direct or indirect genetic interactions between Gli and Bmp genes.

\section{Downstream of BMPs}

BMPs transduce signals through trans-membrane serinethreonine kinase receptors (Massague and Weis-Garcia 19961. These fall into two closely related and conserved groups, known as Type I and Type II, each containing multiple members. The currently favored model for BMP receptor activation differs somewhat from that proposed for TGF $\beta$ receptors. In the case of TGF $\beta$ it is thought that the ligand first binds to a specific Type II receptor followed by recruitment of a Type $\mathrm{I}$ receptor into a heteromeric complex. However, BMP ligands appear to bind cooperatively to both Type I and Type II receptors (Liu et al. 199.5) (Fig. 2). Transphosphorylation of the Type I receptor by the Type II kinase at a specific region (the GS boxl of the cytoplasmic domain then triggers the downstream signaling cascade. Genetic studies in Drosophila have confirmed a requirement for both a Type I encoded by the punt gene) and a Type II (products of the thick veins and saxophone genes) Dpp receptor for signal transduction (Ruberte et al. 1995).

In mammalian cells in vitro the same BMP can recognize more than one Type II receptor, and these, in turn, interact with different Type I family members. Conversely, the same Type II receptor may bind different ligands with different affinities. For example, the Type II Act $R-I I$ receptor binds activin with high affinity and BMP7 with lower affinity (Yamashita et al. 1995). Which receptor combinations occur in vivo, whether different Type I receptors trigger specific downstream pathways, and whether competitive interaction for receptor bind- 


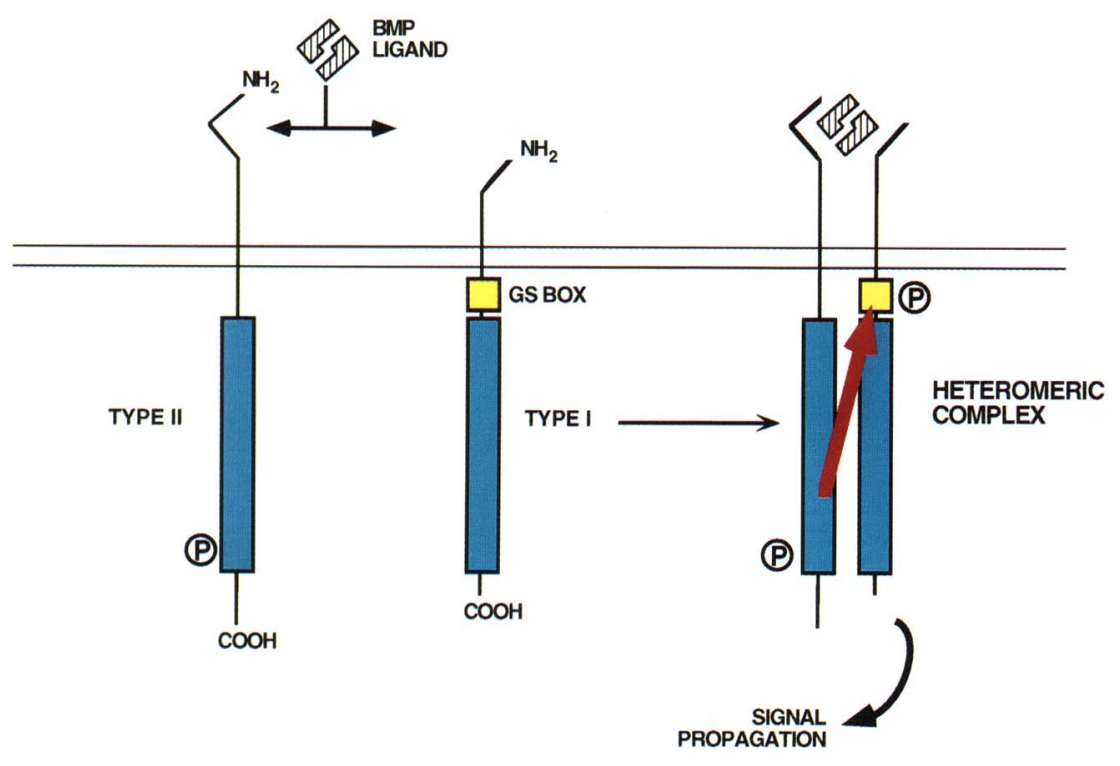

Figure 2. Model for BMP receptor function. According to the currently favored model, signal transduction requires the formation of a heteromeric complex between Type I and Type II trans-membrane serinethreonine kinase receptors. Type II receptors are thought to have constitutive kinase activity, and Type I receptors do not signal until transphosphorylated in the cytoplasmic GS (glycine-serine rich) domain by the Type II kinase. Mutations in the GS domain can generate constitutively active Type I receptors. (Liu et al. 1995; model adapted from Massague and Weis-Garcia 1996). ing between ligands occurs in vivo are some of the many unresolved questions relevant to our understanding of BMP function.

Significant progress has been made in elucidating the downstream pathways involved in the inhibition of cell proliferation by TGF $\beta$ (for review, see Massague and Weis-Garcia 1996). Little is known, however, about signal transduction activated by BMPs. In Drosophila, two genes have been identified that may play a role in the Dpp signaling cascade; these are schnurri (Grieder et al. 1995; Staehling-Hampton et al. 1995), which encodes a protein related to the human zinc-finger transcription factor PRDII/MBPI/HIV-EPI, and mothers-against-dpp (mad) (Raftery et al. 1995; Skelesky et al. 1995), which promotes Dpp activity and encodes a novel intracellular protein. mad-related genes have been identified in Caenorhabditis elegans (Savage et al. 1996) and, recently, as a candidate tumor supressor gene (DPC4) in humans (Hahn et al. 1996). Evidence has also been presented that Ras/Raf/Ap-1 are involved in BMP4 signaling during $X e$ nopus gastrulation (Xu et al. 1996).

Studies in Drosophila have identified a number of genes that are activated in response to Dpp, including the homeo box gene labial in the midgut. Evidence will be presented below that the homeo box genes Msx1 and Msx2 are downstream of BMPs in a number of tissues, including mouse toothbuds, and chick hindbrain and spinal cord (see also Davidson 1995). Homeo box genes are also rapidly activated in Xenopus embryos in response to BMP4 (Gawantka et al. 1995) and activin (Huang et al. 1995; Lemaire et al. 1995/ and Hox genes may be upregulated in the chick limb and gut in response to BMP2 and BMP4 (see below).

\section{BMPs and embryonic development}

In the following sections, evidence for the role of BMPs in embryonic development will be reviewed roughly in chronological order, beginning with gastrulation and concluding with organogenesis.

\section{BMPs and mesoderm formation and patterning in vertebrates}

A current model for the role of signaling molecules in mesoderm induction and patterning in the Xenopus embryo is summarized in Figure 3 (Slack 1994). Starting at the 32- to 64-cell stage, signals from the vegetal blastomeres influence the overlying blastomeres of the animal hemisphere to change their fate from nonspecific ectoderm to ventral-lateral mesoderm (mesothelium, mesenchyme, and blood). Other specific signals from dorsal vegetal blastomeres (the Nieuwkoop center) induce overlying dorsal animal blastomeres to develop into a signaling region known as the Spemann organizer (future dorsal lip of the gastrula). This region secretes dorsalizing factors that appear to have two roles. First, they overcome the ventralized character of the cells in the marginal zone, so that they now give rise to axial mesoderm (notochord), paraxial mesoderm (somite, muscle), and intermediate mesoderm (kidney). The particular fate a marginal zone cell adopts seems to be determined by the balance between the dorsalizing and ventralizing factors to which it is exposed, with the cells closest to the source of dorsalizing signal developing into axial mesoderm and those farthest away developing into mesothelium and blood. Second, as described in the next section, dorsalizing signals appear to interfere with endogenous BMP-related signals acting within the ectoderm to specify it as epidermis, resulting in a switch to neural fate.

The prime candidate for a factor produced by the Nieuwkoop center that induces the Spemann organizer is the BMP family member, $\mathrm{Vg} 1$. However, because $V g 1$ mRNA is distributed evenly throughout the vegetalmost cells, some mechanism must ensure that active mature protein is processed only in the dorsal-vegetal cells (Dale et al. 1993; Thomsen and Melton 1993). In 
Figure 3. Model for the role of signaling molecules in Xenopus gastrulation. Shaded areas represent a fate map of the early gastrula embryo, and arrows represent the influence of signaling molecules. (White arrow) Signal, probably Vgl, possibly in combination with a Wnt-like activity, from the Nieuwkoop center in the vegetal hemisphere induces the formation of the Spemann organizer in the overlying dorsal blastomeres. (Red arrows| The organizer secretes dorsalizing factors that counteract the effect of ventralizing factors in determining cell fate within the presumptive mesoderm of the marginal zone. The same dorsalizing factors also counteract the effect of factors in the ectoderm that promote epidermal cell fate (green) and inhibit neural fate (blue). (Yellow arrow) Ventralizing factors, such as BMP4 and possibly BMP7, promote ventral mesodermal cell fate in the marginal zone. The fate of cells in the marginal zone [dorsal (red)-ventral (yellow) gradient] therefore depends on the relative strength of dorsalizing and ventralizing influences to which they are exposed. This is a simplified and highly schematized model and the effect of these dorsalizing and ventralizing factors is very likely modified by members of other signaling families, including FGFs and Wnts.

addition, it is likely that $\mathrm{Vgl}$ activity is influenced by factors belonging to other highly conserved polypeptide signaling families, such as Wnts and fibroblast growth factors (FGFs). To date, no gene closely related to $V g 1$ has been found in mammalian embryos.

Several lines of evidence suggest that the most potent ventralizing factor is BMP4. This role is consistent with the distribution of $\mathrm{Bmp4}$ transcripts throughout the early gastrula, except in the dorsal lip (Fainsod et al. 1994; Schmidt et al. 1995). It is also compatible with the effects seen when BMP4 activity is either up-regulated by addition of exogenous protein (Koster et al. 1991) or RNA (Dale et al. 1992; Jones et al. 1992), or down-regulated by injection of antisense Bmp4 RNA (Steinbeisser et al. 1995), or dominant-negative BMP receptor RNA (Hemmati-Brivanlou and Melton 1992; Graff et al. 1994; Harland 1994b; Maeno et al. 1994; Suzuki et al. 1994; Schmidt et al. 1995). Recent studies in which Bmp4 expression is driven by a promoter activated during early gastrulation show that production of BMP4 at this stage down-regulates organizer-specific genes such as goosecoid, noggin, and Xnot (Jones et al. 1996). This suggests that during gastrulation, dorsalizing signals have to continually work against ventralizing signals that attenuate their activity. Another recently identified BMP family member, Anti-dorsalizing morphogenetic protein (Admp), has ventralizing activity and perhaps surprisingly is expressed in the dorsal lip itself (Moos et al. 1995). It is possible that Admp acts locally to constrain the action of dorsalizing factors, but its mechanism of action and whether it forms heterodimers with other BMPs is presently unknown.

Several secreted proteins produced in the organizer are candidates for dorsalizing factors in vivo. Of these, Xnrl, $\mathrm{Xnr}$, and Xnr3 are related to mouse Nodal (Jones et al. 1995; Smith et al. 1995) which, as we shall see, has been shown genetically to be required for axial mesoderm formation during gastrulation. Another dorsalizing candi- date is Noggin, a secreted protein with no similarity to TGF $\beta$, which is expressed, among other places, in the dorsal lip, notochord, and prechordal plate (Smith and Harland 1992; Smith et al. 1993; Harland 1994b). In a variety of experimental tests in Xenopus embryos, Noggin counteracts the effect of BMP4; it is likely that Noggin binds to BMP4 protein directly, blocks its biological activity, and restricts the region over which it can act in vivo (Harland 1994b; Re'em-Kalma et al. 1995). Another dorsalizing protein expressed in the dorsal lip and axial mesoderm is the large, multidomain protein Chordin (Sasai et al. 1994). Biological assays involving injection of mRNAs into Xenopus embryos showed that this protein can also counteract the ventralizing effect of BMP4 (Holley et al. 1995). Interestingly, Chordin is related to Sog, the product of a Drosophila gene, short gastrulation, which has been shown genetically to counteract the dorsalizing action of Dpp (Francois and Bier 1995). Interspecific mix and match experiments have demonstrated that Chordin counteracts the dorsalizing action of Dpp, and Sog the ventralizing action of BMP4, in Drosophila and Xenopus embryos, respectively. However, it is currently not known whether this antagonism involves direct protein-protein interaction prior to receptor binding or whether the proteins act through independent receptors.

The conclusion that the counteracting activities of Dpp/BMP4 and Sog/Chordin are apparently conserved between insects and vertebrates has generated substantial interest. It supports the hypothesis that a mechanism for establishing the dorsal-ventral body axis of the embryo evolved in a primitive common ancestor of arthropods and chordates, and that this mechanism was conserved even though the body axes of the two lineages subsequently became inverted relative to each other (for review, see Hogan 1995; De Robertis and Sasai 1996). This raises the interesting possibility that BMP-like proteins were among the first extracellular molecules to be 
used for intercellular signaling and organization in multicellular organisms.

In the mouse, genetic analysis has shown that at least two BMP family members are required for gastrulationNodal and Bmp4. Nodal is required for node and axial mesoderm formation (Conlon et al. 1991, 1994; Zhou et al. 1993). The gene is initially expressed at low levels throughout the embryonic ectoderm but becomes restricted to the primitive streak at gastrulation. Following formation of the node, expression is localized to ventral cells in a horseshoe around the node and asymmetrically in the lateral plate mesoderm. As will be discussed, there is now evidence that Nodal in vertebrates is involved not only in generating axial mesoderm in the anterior-posterior axis, but also in establishing the left-right axis. Indeed, it is likely that the mechanisms for establishing all three axes are tightly interdependent.

Bmp4 is expressed at low levels in the egg cylinder stage embryo prior to gastrulation and then at higher levels in the posterior primitive streak, amnion, and $\mathrm{cx}$ tracmbryonic mesoderm, in the mesoderm around the fore and hindgut, and in the heart (Winnier et al. 1995). The majority of homozygous null $B m p 4$ cmbryos die at or around the time of gastrulation without making embryonic mesoderm, but some do develop up to the early neurula and forelimb bud stage (Winnier et al. 1995). This variability may result from partial rescue by related embryonic or maternal BMPs, an idea supported by the finding that all embryos homozygous for a null mutation in Bmpr, which encodes Bmpr-1A, a Type I BMP receptor, die prior to gastrulation (Mishina et al. 1995). The Bmp4 and Bmpr mutant phenotypes suggest very strongly that BMP4 is required for the proliferation and/ or survival of embryonic ectoderm prior to the onset of gastrulation. This conclusion highlights the link between rapid cell proliferation and the processes of gastrulation and mesoderm formation in the mouse (MacAuley ct al. 1993). The phenotype of those Bmp 4 homozygous mutants that survive beyond gastrulation supports the idea that BMP4 is needed for the proliferation and/or differentiation of extraembryonic mesoderm, including blood islands in the yolk sac, and posterior mesoderm, including that around the hind gut. The extracmbryonic mesoderm deficiency in homozygous mutants is compatible with studies on the effect of BMP4 on the differentiation of $\mathrm{em}$ bryonic stem cells into hematopoietic precursors in vitro (Johansson and Wiles 1995).

Loss-of-function mutations in Bmp2 have also been gencrated, and homozygous mutants die around 9.5 days, with defects in the development of the amnion and heart, two tissues in which the gene is expressed at high levels (H-B. Zhang and A. Bradley, pers. comm.).

\section{Nodal and left-right asymmetry}

One of the most exciting recent findings concerning $B m p$ family members is that Nodal is expressed asymmetrically in the vertebrate embryo, throwing new light on an important but poorly understood phenomenon, the establishment of the left-right axis. The initial observation was made in chick embryos with the nodal-related gene $c N r 1$ (Levin et al. 1995), which is first expressed symmetrically in the primitive streak and then in two distinct domains, a smaller one on the left of the notochord just anterior of the node, and a much larger one in the anterior lateral mesoderm, also on the left side (see Fig. 5C, below). The smaller domain overlaps with asymmetric expression of Shh, and misexpression of Shh on the right side of the embryo leads to ectopic $c N r 1$ expression, suggesting that Shh is normally upstream of CNr1 in the node.

Elegant experiments with a $I a c Z$ reporter gene inserted into the mouse Nodal locus have revealed a transient asymmetry of expression around the node and a second expression domain confined to a subset of lateral plate mesoderm on the left side embryo /Collignon et al. 1996). The Nodal-lacZ mouse will be a powerful tool for analysis of the genetic interactions with other molecular components specifying body situs in vertebrates.

\section{BMPs and neural patterning}

BMPs have been implicated in multiple events during the formation of the central and peripheral nervous system, including primary neural induction, dorsal-ventral patterning of the neural tube, regionalization of the brain, eye development, apoptosis, and lineage determination in the peripheral nervous system.

Primarily from work with amphibians, neural induction has long been thought to result from positive signals from the organizer and axial mesoderm that induce ectoderm to adopt a neural fate. However, more recent expcriments suggest that competitive interactions between epidermalizing and neuralizing factors govern this process (for review, see Harland 1994a). The prime candidate for the epidermalizing factor is BMP4, possibly working together with BMP7. During neurulation, BMP gene transcripts are lost from the presumptive neural tissue and remain expressed only in the epidermis and in dispersed animal cap cultures, BMP4 induces the formation of epidermal cells at the expense of neural cells (Wilson and Hemmati-Brivanlou 1995). Moreover, dominantnegative forms of BMP4, which cannot be cleaved to give mature protein, as well as dominant-negative BMP receptors, induce neural tissue in Xenopus ectoderm (Hawley et al. 1995; Wilson and Hemmati-Brivanlou 1995|. Furthermore, Noggin, Chordin, and Follistatin are all thought to induce neural tissue by inhibiting BMP4 activity, either by binding directly to the protein or by competing at the level of receptors (Lamb et al. 1993; Hemmati-Brivanlou et al. 1994; Sasai et al. 1994, 1995). Thus, BMP4 promotes the formation of epidermis, and when signaling is disrupted, ectoderm forms neural tissue. It is still unclear whether limiting BMP activity is sufficient for the formation of neural tissue in vivo, or if positive neuralizing factors, for example, nodal-related proteins, are still necessary. Interestingly, however, these data suggest that the same system of counteracting molecules is used to pattern both the mesoderm and the ectoderm (De Robertis and Sasai 1996).

Studies mainly with chick embryos have implicated BMPs in dorsal-ventral patterning of the neural tube. In 
the chick, both $B m p 4$ and $B m p 7$ are expressed in the non-neural ectoderm bordering the neural plate. As the plate rolls up into a tube, transcript levels of both genes decline in the epidermis, except for $B m p 7$ in the forebrain region. However, high levels of $B m p 4$ expression are seen in the dorsal neural folds and midline of the neural tube as it closes (Licm et al. 1995). Later, Dorsalin 1 (Dsl1) is expressed along the dorsal midline. A somewhat different pattern is seen in the mouse, in which $B m p 2$ rather than $B m p 4$ is initially expressed in the neural folds, at least in the anterior regions (Winnier et al. 1995|. After neural tube closure, Bmp4 is expressed in the dorsal midline anteriorly, and $B m p 6$ along the whole axis (Jones et al. 1991; Y. Furuta and B.L.M. Hogan, unpubl.). Experiments initially performed with chick spinal cord explants and Dsll indicated that the protein could both induce the formation of dorsal cell types, as well as antagonize ventralizing signals from the notochord/floor plate (Basler et al. 1993). However, more recent experiments have shown that earlier signals from the non-neural ectoderm are important for establishing dorsal identity within the neural tube. These signals induce the formation of neural crest cells, as well as dorsal spinal cord markers such as Wnt1/3a, Pax3, and Msx1/2. The inductive effect of non-neural ectoderm can apparently be mimicked by BMP4 and BMP7, which, at least in the chick, are both expressed at the right time and place to be dorsalizing signals (Dickinson et al. 1995; Liem et al. 1995; for review, sec Lumsden and Graham 1995).

It has been suggested that in vivo, BMPs act to inhibit the spread of ventralizing signal|s\} from the floorplate throughout the neural tube (Liem et al. 1995). A variety of experimental observations show that Shh, produced by the notochord and floorplate, is a long-range ventralizing signal for the spinal cord (Roelink et al. 1994, 1995), possibly acting by a ptc-dependent pathway /Goodrich et al. 1996). In vitro data from chick spinal cord explant cultures suggest that BMP4 and Shh/notochord have mutually antagonistic effects on neural tube patterning (Liem et al. 1995), but it is not yet known whether these results reveal the real roles of the two proteins in normal development. In vivo, for example, the non-neural ectoderm and floorplate are separated by a significant distance. Nevertheless, it is interesting to note that the effect of Shh in the spinal cord is to antagonize the effect of BMP4, whereas in other tissues Shh has been reported to induce expression of BMPs in neighboring cells.

In addition to an effect on dorsal-ventral patterning of the neural tube, BMP-encoding genes may be involved in regional neural development. Several BMP-encoding genes are expressed in localized regions of the fore and midbrain in the mouse embryo, including $B m p 4, B m p 5$, Bmp6, and Bmp7 (Jones et al. 1991; King et al. 1994; Dudley et al. 1995; Luo et al. 1995). However, the domains of expression have not been mapped precisely and, with the exception of $B m p 7$, neurogenic roles for the genes have not yet been defined. Bmp7 null embryos have severe defects in eye development (Dudley et al. 1995; Luo et al. 1995). The initial outgrowth of the optic vesicle, formation of the optic cup, and lens induction, all appcar to be normal up to around $11.0 \mathrm{dpc}$ but these structures subsequently degenerate, indicating that BMP7 acts to maintain their survival.

Finally, BMP4 has been implicated in regional apoptosis in the nervous system. In the chick embryo, $B m p 4$ is expressed at high levels in the dorsal region of rhombomeres 3 and 5. These rhombomeres are distinguished by the fact that the cells that normally differentiate into neural crest cells undergo apoptosis. Addition of BMP4 to rhombomere cultures induces $M s \times 2$ expression and apoptusis (Graham et al. 1993). Apoptosis plays a key role in the morphogenesis of other regions of the brain, but it is not yet known whether this apoptosis is mediated by BMP4.

\section{BMPs and somite patterning}

The paired somites on either side of the neural tube give rise to a variety of differentiated derivatives; the ventral region disperses to generate the sclerotome, which gives rise to the vertebrae, while the dorsal region produces the dermomyotome, the precursor of both dermis and muscle. There is also mediolateral patterning of the somite, with medial myotome giving rise to axial muscles and lateral myotome producing muscles in the body wall and limbs. Sclerotome cells are induced by notochord- and floorplate-derived signals, such as Shh, whereas more dorsal cells are induced by an as-yet-unidentificd signal from the overlying non-neural ectoderm (Fan and Tessier-Lavigne 1994; Johnson et al. 1994a; Fan et al. 1995). Medial patterning, as judged by expression of the myogenic marker, $M y o D$, is promoted by a signal from the dorsal neural tube, possibly a Wnt family member (Munsterberg et al. 1995), while lateral patterning, inducing expression of the marker Siml, is effected by a signal from the lateral plate mesoderm, a tissue that expresse's high levels of Bmp4 (Cossu et al. 1996; I'ourquie et al. 1996; Spence and Erickson 1996). Recent experiments show that the lateral signal can be mimicked by implanting $B m p 4$-expressing cells into the embryo between the neural tube and the somite (Pourquie et al. 1996). The apparent discrepancy in the findings that BMP4 is expressed in the dorsal ectoderm and neural tube (see previous section) but apparently functions as a lateralizing factor for the somite may be explained by differences in the timing at which dorsal-ventral and mediolateral patterning occur.

\section{BMPs in skeletal development}

Several BMP-encoding genes were first identified on the basis of their ability to induce ectopic endochondral bone. However, surprisingly little is known about the cellular and molecular mechanisms involved either in ectopic or normal bone development. Several mechanisms have been proposed. One is that BMPs act on uncommitted multipotent stcm cells to promote their entry into the chondrogenic or osteogenic, rather than myogenic or adipogenic pathways (Yamaguchi et al. 1991; Gimble et al. 1995). Alternatively, BMPs may stimulate cells committed to the chondrogenic and os- 
teogenic lineages, and promote programmed cell death or transdifferentiation of cells committed to other lineages (Katagiri et al. 1994; Duprez et al. 1996).

Studies on chondroblast or osteoblast cell lines or primary cultures show that BMPs stimulate the expression of markers of the differentiated phenotype alkaline phosphatase, osteocalcin synthesis, cAMP response to parathyroid hormone, collagen synthesis, formation of cartilage nodules) possibly via induction of Msx genes (for review, see Davidson 1995) but have only modest stimulatory effects on cell proliferation /Vukicevic et al. 1989; Sampath et al. 1992; Thies et al. 1992; Asahina et al. 1993; Harris et al. 1995).

One problem in understanding the role of BMPs in skeletal development is that relatively little information is available on the comparative expression patterns of ligands, receptors, and potential binding proteins in the many different populations of cells involved. As shown in Figure 4 and elsewhere (Yamaii et al. 1994; Luo et al. 1995; Lyons et al. 1995), the temporal and spatial patterns of expression in embryonic mouse forelimbs of $B m p 2, B m p 4$, and $B m p 7$ are complex and involve different cell populations at different developmental stages. Insight is likely to come from the generation and crossbreeding of mutant mice with defects in skeletogenesis. For example, analysis of mice with loss-of-function mutations in Bmp5 [short ear [se)] (Kingsley et al. 1992; King et al. 1994) and Gdf5 (brachypodism) (Storm et al. 1994) show that specific subsets of skeletal elements require different BMP family members for normal development.

\section{Limb patterning}

The patterning of the limb bud is one of the most intensively studied examples of morphogenesis in vertebrates (Duboule 1994; Johnson et al. 1994b; Tickle 1995). Patterning is generated through a network of reciprocal interactions between four signaling tissues: (1) the dorsal and ventral ectoderm, which largely controls dorsal-ventral patterning; (2) the apical ectodermal ridge (AER), a specialized region of the distal ectoderm that maintains proximal-distal outgrowth of the limb and expresses high levels of FGF4 and FGF8; (3) the progress zone, a region of mesenchyme subjacent to the AER, in which cells proliferate and maintain an undifferentiated state, expressing high levels of Msx1 and Wnt5a; and (4) the zone of polarizing activity $(\mathrm{ZPA})$ in the posterior mesenchyme, which produces Shh as a soluble signal regulating anterior-posterior polarity within the limb bud.

$B m p 2, B m p 4$, and $B m p 7$ are all expressed in the AER, where they may function in controlling cell proliferation and/or in signaling to the progress zone. In the mesenchyme of the limb, however, these three genes have significantly different patterns of expression, as shown for the mouse embryo in Figure 4. High levels of Bmp4 RNA are seen in the posterior and anterior mesenchyme, and in the progress zone underneath the AER, where expression persists until beyond $13.5 \mathrm{dpc}$. Later, expression is also seen in the developing joints and the ventral footpads. Bmp2 is first expressed in regions of the posterior mesenchyme, and by $12.5 \mathrm{dpc}$, high levels of transcripts are seen around the digit rudiments and, later, in the joints and footpads. Bmp7 RNA is first seen diffusely throughout the limb bud mesenchyme and then at high levels around the digit rudiments and in the interdigital mesenchyme, where there is normally a high rate of programmed cell death (Luo et al. 1995; Lyons et al. 1995; Mori et al. 1995). Similar but not identical patterns have been reported for the early chick wing and hind limb (Francis et al. 1994; Laufer et al. 1994; Zou and Niswander 1996).

Experimental embryological studies on the chick wing bud have shown that ectopic ZPA grafts or Shh in the anterior mesenchyme will induce Bmp2 expression in adjacent cells. This response requires FGF produced by the AER. BMP2 may then act as a secondary signaling molecule, playing a role in inducing nested expression of Hoxd11-Hoxd13 in mesenchyme cells (Francis et al. 1994; Laufer et al. 1994). Indeed, recent experiments have shown that ectopic expression of Bmp2 in the anterior mesenchyme induces $f g f 4$ transcripts in the AER and Hoxd13 in the mesenchyme (Duprez et al. 1996: These investigators propose a model for the role of multiple signaling molecules in mediating the interactions between the AER and mesenchyme during limb patterning.

Loss-of-function Bmp2 mutant mice die around 9.5 dpc so that they do not help decipher the role of this factor in mouse limb patterning. In contrast, $B m p 7$-null mutant mice survive to birth and show unilateral or bi-

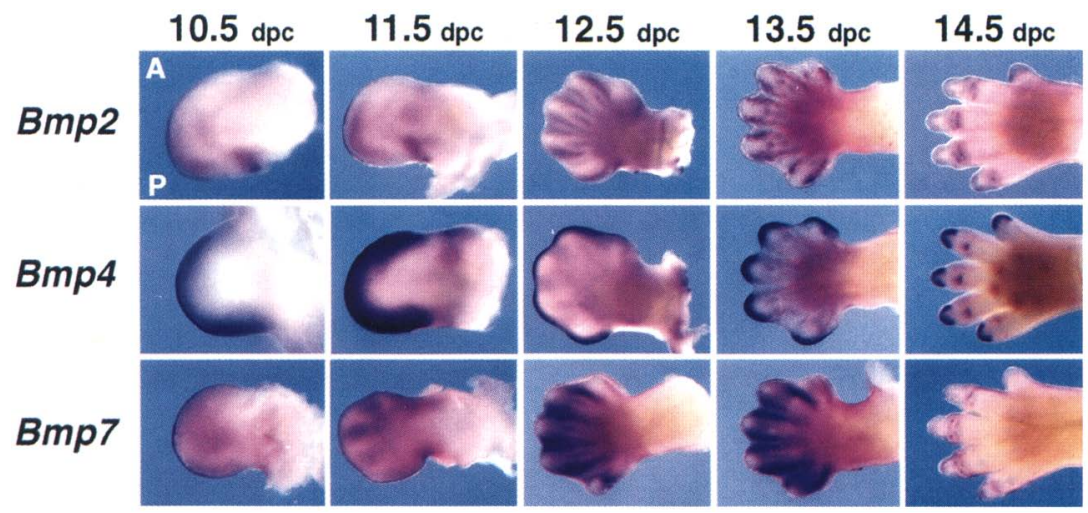

Figure 4. Expression of BMPs during mouse limb development. Whole-mount in situ hybridization was used to show the distribution of RNA for $B m p 2, B m p 4$, and $B m p 7$ in mouse embryo forelimbs at different stages of development. In all panels, anterior is to the top and posterior to the bottom, and all except Bmp 4 at $14.5 \mathrm{dpc}$ are dorsal views (figure provided by Glenn Winnier, Vanderbilt Medical School, Nashville, TN). 
lateral hindlimb polydactyly involving the presence of a single extra preaxial (anterior) digit (Dudley et al. 1995; Luo et al. 1995|. The absence of webbing indicates that interdigital cell death occurs normally in the mutant while the polydactyly suggests that $B m p 7$ normally restricts cell proliferation in the developing limb; in the absence of ligand excessive mesenchyme cells may accumulate, allowing the formation of an extra digit. This hypothesis is supported by the finding that in the chick wing bud, $B m p 2$ inhibits cell growth in the absence of an AER and counteracts the effect of FGF (Niswander and Martin 1993). However, it does not adequately explain why polydactyly is only preaxial. An alternative hypothesis is that $B m p 7$ affects the expression of Hox genes, which are thought to control both cell proliferation and tissue patterning within the limb (Duboule 1994). Preliminary evidence shows that the expression pattern of Hoxd13 is altered in Bmp7-null mutants (Luo ct al. 19951 .

Recent experiments in which dominant-negative BMP2/BMP4/BMP7 Type I receptors are expressed in the developing chick hind limb with retroviral vectors support a role for BMPs in regulating the apoptosis that normally occurs between the digits (Zou and Niswander 1996|. The results also suggest that BMPs regulate the differentiation of the surface ectoderm into feathers or scales.

Although we have some clues about BMP function in the vertebrate limb, there is obviously a long way to go before the final story can be told. For example, it scems likely that BMP function is modified by other signaling molecules such as Wnt7a, which is expressed in the dorsal ectoderm and required for dorsal-ventral limb patterning (Parr and McMahon 1995; Riddle et al. 1995; Yang and Niswander 19951, Wnt5a, which is expressed in the distal mesenchyme and ventral ectoderm (Parr et al. 1993), and FGFs, which are expressed in the early mesenchyme and in the AER. It is interesting to note that in the development of both insect and vertebrate legs many of the signaling molecules used, such as $\mathrm{Hh} / \mathrm{Shh}$, Dpp/ $\mathrm{BMP} 2$ and BMP4, $\mathrm{Wg} / \mathrm{Wnts}$, and Engrailed (En/Enl), are closely related. Moreover, in both cases, distal outgrowth is organized from boundary regions where $d p p /$ Bmp-and wg/Wnt-expressing domains interface (Held 1995). However, although tempting to do so, it is probably too early to draw detailed analogies between the patterning of vertebrate and insect legs.

\section{BMPs and organogenesis}

There is now considerable evidence that BMPs are required for the development of many organs, including the kidney, lung, heart, teeth, gut, and skin. In particular, BMPs may help mediate the inductive interactions between mesenchymal and epithelial cells in these tissues, as well as controlling cell proliferation and apoptosis. Furthermore, in some organs that undergo branching or complex morphogenesis, BMPs are expressed by relatively small groups of cells that may behave as organizing centers.

\section{Kidney development}

Many BMPs are expressed in the embryonic kidney and urinary system $(B m p 3, B m p 4, B m p 5, B m p 6, B m p 7$, and gdnf) (King et al. 1994; Bitgood and McMahon 1995; Dudlcy et al. 1995; Luo et al. 1995). Genetic evidence demonstrates a role for $B m p 5$ in ureter development (King et al. 1994) and Bmp7 in nephrogenesis (Dudley et al. 1995; Luo et al. 1995). Development of the metanephric kidney is initiated by the growth of the ureteric bud into the metancphric mesenchyme. Reciprocal interactions between the two tissues result in the branching of the ureteric bud and the formation of distal condensations of mesenchymal cells that then differentiate into epithelial structures. Bmp 7 is first expressed in the metancphric duct and later in the nephrogenic mesenchyme, the condensing aggregrates, the epithelial tubules, and the podocytes of the glomeruli (Fig. 5A). Mice homozygous for a null mutation in $B m p 7$ die soon after birth because of renal failure. Kidney development is essentially normal until around $14.5 \mathrm{dpc}$, but then branching of the ureteric epithelium, formation of mesenchymal condensations, and differentiation of epithelial structures, all tissues in which $B m p 7$ is expressed, all cease. The mutant kidneys suffer massive apoptosis of the disorganized, uninduced mesenchymal cells (Luo et al. 1995/ showing that BMP7 is necessary for their continued proliferation, differentiation, and survival. However, the precise reason for this death, and why inductive interactions can proceed for a while before ceasing, are still unclear. It is possible that other BMPs expressed in the developing kidney compensate for the absence of BMP7 early in development but cannot suffice as the number of end buds increases.

\section{Tooth development}

During tooth formation, an epithelial placode penetrates into the underlying mesenchyme, which condenses around the plug. The ectodermal bud first forms a cap and then a bell-shaped structure. Subsequently, the mesenchymal papilla differentiates into an epithelial layer |the future odontoblasts| in apposition with the overlying ectoderm (the future ameloblasts). Gene expression patterns (Vainio et al. 1993; Bitgood and McMahon 1995; Vaahtokari et al. 1996a) and the effect of purified protein in vitro (Vainio et al. 1993) have implicated BMPs at several different stages in tooth development, in cell proliferation, apoptosis, epithelial-mesenchymal interactions, and differentiation. At the bud and cap stages, cells which express $S h h, B m p 2, B m p 4, B m p 7$, and FGF4 are tightly localized in nested domains in a central region of the ectodermal epithelium known as the enamel knot (Vaahtokari et al. 1996a) (Fig. 5B). Moreover, the cells in the knot have a significantly slower rate of proliferation than the surrounding epithelium. It has been suggested that the enamel knot is an organizing center for the tooth and plays a crucial role in the morphogenesis from the cap to the bell stage by locally controlling cell proliferation. The precise role of BMPs in the enamel knot 


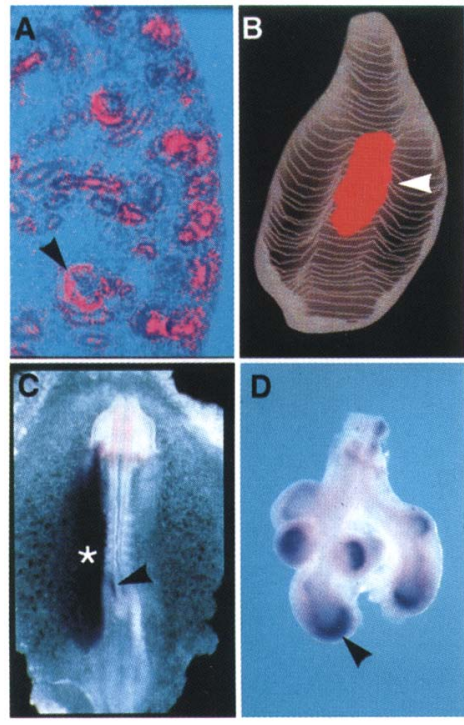

Figure 5. Expression of BMP gene family members during embryogenesis. $|A| B m p 7$ expression in the 13.5 dpc mouse kidney. High levels of transcript are seen in the ureteric epithelium, condensing mesenchyme, comma and S-shaped bodies, and proximal and distal tubules, as well as the podocytes of the glomerulus (arrow) (figure provided by A. Dudley and E. Robertson, Harvard University, Cambridge, MA). (B) Computer reconstruction of Bmp4 expression (arrow) in the $14.0 \mathrm{dpc}$ mouse first molar tooth at the cap stage. Transcripts are localized to a subdomain of the enamel knot (modified, with permission, from Vaahtokari et al. 1996a). (C) Expression of Nodal in the stage 8+ ( $28 \mathrm{hr}$ ) chick embryo visualized by whole-mount in situ hybridization. Two asymmetric expression domains are seen, a smaller one in the mesoderm adjacent to the left side of Hensen's node (arrow), and a second, much broader domain encompassing the entire lateral plate mesoderm on the left side of the embryo (figure provided by Cliff Tabin, Harvard Medical School, Boston, MA). (D) Bmp4 expression in a lung from a 11.5 dpc mouse embryo visualized by whole-mount in situ hybridization. RNA is present at the distal tips of the lung buds (arrow), in both the endoderm and adjacent mesenchyme (modified from Bellusci et al. 1996).

and their relationship to other signaling molecules is not yet known. BMP2 may inhibit proliferation in the epithelium, for example, whereas BMP4 may regulate the onset of the apoptosis, terminating the signaling function of the knot (Vaahtokari et al. 1996b).

BMP4 may also play an important role in the earliest epithelial-mesenchymal interactions that initiate tooth development. When tooth germs are exposed in vitro to BMP2 or BMP4 protein adsorbed onto beads, mimicking the epithelial BMP4 signal from the invading placode, the expression of both Bmp4 and the homeo box genes Msx1 and Msx2 is induced in the underlying condensing mesenchyme (Vainio et al. 1993). The functional significance of this induction is supported by the finding that Msx1-deficient mouse embryos show a failure in tooth development (Satokata and Maas 1994). Finally, at the late bell stage, Shh, Bmp2, and Bmp4 are expressed in the odontoblast and ameloblast layers, suggesting that they may be involved in the proliferation and/or differentia- tion of these specialized cells /Vainio et al. 1993; Bitgood and McMahon 1995).

\section{Lung development}

The lung develops from a bud of foregut endoderm surrounded by splanchnic mesoderm, and tissue reconstitution experiments have demonstrated critical interactions between these two cell layers for normal branching morphogenesis. Transcripts for Bmp4, Bmp5, and Bmp 7 have been detected in specific patterns in the embryonic lung (King et al. 1994; Bitgood and McMahon 1995; Bellusci et al. 1996). Interestingly, Bmp4 RNA is restricted to the tips of the distal buds and the adjacent mesenchyme (Fig. 5). If $\mathrm{Bmp} 4$ is ectopically expressed throughout the distal epithelium of the lung buds in transgenic embryos, branching morphogenesis is severely disrupted, resulting in the formation of large, dilated sacs (Bellusci et al. 1996). Proliferation of the endoderm is also inhibited, whereas that of the mesenchyme is stimulated. These observations support a model for normal development in which $B m p 4$ expression at the tips of the lung buds locally inhibits endoderm proliferation and forces outgrowth of lateral branches. This model is similar to that proposed for the role of BMPs in the enamel knot of the tooth bud. The relationship between BMP4 in the lung and other signaling molecules, in particular Shh, which is also expressed at high levels in the distal epithelium, remains to be seen.

\section{Gut development}

The gut develops ventrally from an endodermal tube surrounded by splanchnic mesoderm, and tissue reconstitution experiments have provided extensive evidence for reciprocal inductive interactions between these two layers. In both early chick and mouse embryos Shh is expressed at high levels in the endoderm of the fore- and hindgut and $B m p 4$ is expressed at high levels in the surrounding mesoderm (Jones et al. 1991; Echelard et al. 1993; Roberts et al. 1995; Winnier et al. 1995). Later in development, localized expression of $S h h$ and $I h h$ and Bmp4 (Bitgood and McMahon 1995) is seen in regions of the gut such as the stomach. Studies with the chick embryo have shown that ectopic expression of Shb in the endoderm (and mesoderm) anterior of the hindgut, induces $B m p 4$ transcripts in the surrounding splanchnic mesoderm. Ectopic Shh also induces Hoxd13 expression in the adjacent mesoderm, although it is not known whether $\mathrm{Bmp} 4$ acts as a secondary signal in this induction. If this proves to be the case, it would support an interesting analogy that has been made (Roberts et al. 1995) between hindgut patterning in vertebrates and midgut patterning in Drosophila, where Dpp mediates inductive interactions between mesoderm and endoderm, resulting in the activation of the homeo box gene labial.

\section{Other organs and tissues}

BMPs are expressed in many organs and tissues besides those discussed above, including skin and hair, and the 
germ cells of the ovary and testis. Overexpression of Bmp4 in the outer root sheath of the hair in transgenic mice results in inhibition of proliferation in the hair sheath and hair loss (Blessing et al. 1993) and a block in papilloma formation in response to chemical carcinogen treatment and promotion (Blessing et al. 1995). The relationship between BMP and Shh expression in the hair is not yet clear (Bitgood and McMahon 1995). Growth and Differentiation Factor $9(G d f 9)$ is expressed specifically in oocytes in the ovary (McGrath et al. 1995), and $B m p 8 a$ and $B m p 8 b$ are expressed in the germ cells of the testis (Zhao and Hogan 1996). Inactivation of the Bmp8b gene leads to defects in spermatogenesis and to male infertility (Zhao et al., this issue).

\section{Future direction for BMP research}

Because members of the BMP superfamily are required for the development of a wide range of organs and tissues, there is enormous incentive to understanding precisely how they function. Within a few years loss-offunction mutations in all of the genes encoding ligands, receptors, and presumptive binding proteins should be generated in mice, and their individual phenotypes should provide a wealth of information. In particular, the generation of compound mutants, or the replacement of one gene by another through knock-in techniques (Hanks et al. 1995), should throw light on interactions between different factors and the extent to which one BMP functionally replaces another. Expression of ligands and dominant-negative receptors in specific tissues in transgenic mice will also be an important tool. It is also vital to learn more about the role of extracellular binding proteins and matrix components in controlling the availability of BMPs, and whether heterodimers have significantly different activities from homodimers in vivo.

Some of the biggest gaps in our present knowledge relate to the mechanisms regulating the expression of $B m p$ genes in vivo and the downstream signal transduc. tion pathways leading from the BMP receptors at the cell surface to the activation of specific genetic programs in the nucleus. In addition, it will be interesting to sce how combinations of different cytokines, for example members of the TGF $\beta$, Wnt, FGF, and Hh superfamilies, can affect the fate of individual cells. But perhaps the greatest need is for more information about how combinations of these signaling molecules are used to organize patterns in embryonic tissues. Extensive studies in Drosophila have shown that boundaries between cellular domains expressing different signaling molecules play key roles in establishing and refining patterns of differential cell fate in the embryo. It will be exciting to see whether similar boundaries are important as organizing centers in vertebrate morphogenesis.

\section{Acknowledgments}

I thank members of my laboratory and Drs. Christopher Wright, Elizabeth Robertson, Mary Dickinson, and Karen Lyons for constructive and critical comments, and stimulating discussions. Many colleagues helpfully provided reprints, and preprints of their work. Thanks also go to Drs. Vicki Rosen and Anthony Celeste, Genetics Institute, for help with Figure 1, to Glenn Winnier, Andrew Dudley, Elizabeth Robertson, and Cliff Tabin for figures, and to Julie Kopioe and Paul Matrisian for help with preparing the manuscript. B.L.M.H. is an Investigator of the How ard Hughes Medical Institute.

\section{References}

Asahina, I, T.K. Sampath, I. Nishimura, and P.V. Hauschka. 1993. Human osteogenic protein-1 induces both chondroblastic and osteoblastic differentiation of osteoprogenitor cells derived from newborn rat calvaria. /. Cell Biol. 123: 921-933.

Barr, P.J 1991. Mammalian subtilisins: The long-sought dibasic processing endoproteases. Cell 66: 1-3.

Basler, K., T. Edlund, T.M. Jessell, and T. Yamada. 1993. Control of cell pattern in the neural tube: Regulation of cell differentiation by dorsalin- 1 , a novel Tgf $\beta$ family member. Cell 73: 687-702.

Bellusci, S., R. Henderson, G. Winnier, T. Oikawa, and B.L.M. Hogan. 1996. Evidence from normal expression and targeted misexpression that bone morphogenetic protein-4 (Bmp-4) plays a role in mouse embryonic lung morphogenesis. Development 122: 1693-1702.

Bienz, M. 1994. Homeotic genes and positional signalling in the Drosophila viscera. Trends Genet. 10: 22-26.

Bitgood, M.I. and A.P. McMahon. 1995. Hedgehog and Bmp genes are coexpressed at many diverse sites of cell-cell interaction in the mouse embyro. Dev. Biol. 172: 126-138.

Blessing, M., L.B. Nanney, L.E. King, and B.L.M. Hogan. 1995. Chemical skin carcinogenesis is prevented in mice by the induced expression of a Tgf $\beta$ related transgene. Teratog. Carcinog. Mutagen. 15: 11-21.

Blessing, M., L.B. Nanney, L.E. King, C.M. Jones, and B.L.M. Hogan. 1993. Transgenic mice as a model to study the role of Tgi- $\beta$-related molecules in hair follicles. Genes \& Dev. 7:204-215.

Bonini, N.M. and K.W. Choi. 1995. Early decisions in Drosophila eye morphogenesis. Curr. Opin. Genet. Dev. 5: 507-515.

Capovilla, M., M. Brandt, and J. Botas. 1994. Direct regulation of decapentaplegic by Ultrabithorax and its role in Drosophila midgut morphogenesis. Cell 76: 461-475.

Childs, S.R., and M.B. O'Connor. 1994. Two domains of the tolloid protein contribute to its unusual genetic interaction with decapentaplegic. Dev. Biol. 162: 209-220.

Collignon, I., I. Varlet, and E. Robertson. 1996. Relationship between asymmetric nodal expression and the direction of embryonic turning. Nature 381: 155-158.

Conlon, F.L., K.S. Barth, and E.J. Robertson. 1991. A novel retrovirally induced embryonic lethal mutation in the mouse: Assessment of the developmental fate of embryonic stem cells homozygous for the 413 .d proviral integration. Development 111: 969-981.

Conlon, F.L., K.M. Lyons, N. Takaesu, K.S. Barth, A. Kispert, B. Herrmann, and E.J. Robertson. 1994. A primary requirement for nodal in the formation and maintenance of the primitive streak in the mouse. Development 120: 1919-1928.

Cossu, G., R. Kelly, S. Tajbakhsh, S.D. Donnia, E. Vivarelli, and M. Buckingham. 1996. Activation of different myogenic pathways: myf -5 is induced by the neural tube and MyoD by the dorsal ectoderm in mouse paraxial mesoderm. Development 122: 429-437.

Dale, L., G. Howes, B.M.J. Price, and J.C. Smith. 1992. Bone morphogenetic protein 4 : A ventralizing factor in early Xenopus development. Development 115: 573-585.

Dalc, L., G. Matthews, and A. Colman. 1993. Secretion and 
mesoderm-inducing activity of the Tgf- $\beta$-related domain of Xenopus Vg1. EMBO /. 12:4471-4480.

Daopin, S., K.A. Piez, Y. Ogawa, and D.R. Davies. 1992. Crystal structure of transforming growth factor- $\beta 2$ : An unusual fold for the superfamily. Science 257: 369-373.

Davidson, D. 1995. The function and evolution of $M s \times$ genes: Pointers and paradoxes. Trends Genet. 11:405-411.

De Robertis, E.M. and Y. Sasai. 1996. A common plan for dorsoventral patterning in Bilateria. Nature 380: $37-40$.

Dickinson, M.E., M.A.J. Selleck, A.P. McMahon, and M. Bronner-Fraser. 1995. Dorsaliziation of the neural tube by nonneural ectoderm. Development 121: 2099-2106.

Duboule, D. 1994. How to make a limb! Science 266: 575-576.

Dudley, A.T., K.M. Lyons, and E.J. Robertson. 1995. A requirement for bone morphogenetic protein-7 during development of the mammalian kidney and eye. Genes \& Dev. 9: 27952807.

Duprez, D.M., M. Coltey, H. Amthor, P.M. Brickell, and C. Tickle. 1996. Bone morphogenetic protein-2 (Bmp-2) inhibits muscle development and promotes cartilage formation in chick limb bud cultures. Dev. Biol. 174: 448-452.

Duprez, D.M., K. Kostakopoulou, P.H. Francis-West, and C. Tickle. 1996. Activation of Fgf- 4 and HoxD gene expression by Bmp-2 expressing cells in the developing chick limb. Development 122: 1821-1828.

Echelard, Y., D.J. Epstein, B. St Jacques, L. Shen, J. Mohler, J.A. McMahon, and A.P. McMahon. 1993. Sonic hedgehog, a member of a family of putative signaling molecules, is implicated in the regulation of CNS polarity. Cell 75: 14171430.

Fainsod, A., H. Steinbeisser, and E.M. de Robertis. 1994. On the function of $B m p-4$ in patterning the marginal zone of the Xenopus embryo. EMBO 1. 13: 5015-5025.

Fan, C.-M. and M. Tessier-Lavigne. 1994. Patterning of mammalian somites by surface ectoderm and notochord: Evidence for sclerotome induction by a hedgehog homolog. Cell 79: $1175-1186$.

Fan, C.-M., J.A. Porter, C. Chiang, D.T. Chang, P.A. Beachy, and M. Tessier-Lavigne. 1995. Long-range sclerotome induction by Sonic hedgehog: Direct role of the amino-terminal cleavage product and modulation by the cyclic AMP signaling pathway. Cell 81: 457-465.

Ferguson, E.L. and K.V. Anderson. 1992. decapentaplegic acts as a morphogen to organize dorsal-ventral pattern in the Drosophila embryo. Cell 71: 451-461.

Finelli, A.L., C.A. Bossie, T. Xie, and R.W. Padgett. 1994. Mutational analysis of the Drosophila tolloid gene, a human Bmp-1 homolog. Development 120: 861-870.

Forbes, A.J., Y. Nakano, A.M. Taylor, and P.W. Ingham. 1993. Genetic analysis of hedgehog signalling in the Drosophila cmbryo. Development (Suppl.) 115-124.

Francis, P.H., M.K. Richardson, P.M. Brickell, and C. Tickle. 1994. Bone morphogenetic proteins and a signalling pathway that controls patterning in the developing limb bud. Devel. opment 120: 209-218.

Francois, V. and E. Bier. 1995. Xenopus chordin and Drosophila shart gastrulation genes encode homologous proteins functioning in dorsal-ventral axis formation. Cell 80: 19-20.

Gawantka, V., H. Delius, K. Kirschfeld, C. Blumenstock, and C. Niehrs. 1995. Antagonizing the Spemann organizer: Role of the homeobox gene Xvent-1. EMBO I. 14: 6268-6279.

Gimble, J.M., C. Morgan, K. Kelly, X. Wu, V. Dandapani, C.-S. Wang, and V. Rosen. 1995. Bone morphogenetic proteins inhibit adipocyte differentiation by bone marrow stromal cells. f. Cell. Biochem. 58: 393-402.

Gitelman, S.E., M.S. Kobrin, J.Q. Ye, A. Lee, and R. Derynck.
1994. Recombinant Vgr-1/BMP-6 expressing tumors induce fibrosis and endochondral bone formation in vivo. $/$. Cell Biol. 126: 1595-1609.

Goodrich, L.V., R.L. Johnson, L. Milenkovic, J.A. McMahon, and M.P. Scott. 1996. Conservation of the hedgehog/patched signaling pathway from flies to mice: Induction of a mouse patched gene by Hedgehog. Genes \& Dev. 10: 301-312.

Graff, I.M., R.S. Thies, J.J. Song, A.J. Celeste, and D.A. Melton. 1994. Studies with a Xenopus BMP receptor suggest that ventral mesoderm-inducing signals override dorsal signals in vivo. Cell 79: 169-179.

Graham, A., I. Heyman, and A. Lumsden. 1993. Even-numbered rhombomeres control the apoptotic elimination of neural crest cells from odd-numbered rhombomeres in the chick hindbrain. Development 119: 233-245.

Green, J.B.A., H.V. New, and I.C. Smith. 1992. Responses of embryonic xenopus celis to activin and Fgf are separated by multiple dose thresholds and correspond to distinct axes of the mesoderm. Cell 71: 731-739.

Gricder, N.C., D. Nellen, R. Burke, K. Basler, and M. Affolter. 1995. Schnurri is required for Drosophila Dpp signaling and encodes a zinc finger protein similar to the mammalian transcription factor PRDII-BFI. Cell 81: 791-800.

Griffith, D.L., P.C. Keck, T.K. Sampath, D.C. Rueger, and W.D. Carlson. 1996. Three-dimensional structure of recombinant human osteogenic protein 1: Structural paradigm for the transforming growth factor superfamily. Proc. Natl. Acad. Sci. 93: 878-883.

Gurdon, I.B., P. Harger, A. Mitcheil, and P. Lemaire. 1994. Activin signalling and response to a morphogen gradient. $\mathrm{Na}$ ture 371: 487-492.

Gurdon, I.B., A. Mitchell, and D. Mahony. 1995. Direct and continuous assessment by cells of their position in morphogen gradient. Nature 376: 520-521.

Hahn, S.A., M. Schutte, A.T.M. Shamsul Hoque, C.A. Moskaluk, L.T. da Costa, E. Rozenblum, C.L. Weinstein, A. Fischer, C.J. Yeo, R.H. Hruban, and S.E. Kern. 1996. DPC4, a candidate tumor suppressor gene at human chromosome 18q21.1. Science 271: 350-353.

Hanks, M., W. Wurst, L. Anson-Cartwright, A.B. Auerbach, and A.L. Joyner. 1995. Rescue of the En-1 mutant phenotype by replacement of En-1 with En-2. Science 269: 679-682.

Harland, R.M. 1994a. Neural induction in Xenopus. Curr. Opin. Genet. Dev. 4: 543-549.

1994b. The transforming growth factor $\beta$ family and induction of the vertebrate mesoderm: Bone morphogenetic proteins are ventral inducers. Proc. Natl. Acad. Sci. 91: $10243-10246$.

Harris, S.E., J.Q. Feng, M.A. Harris, N. Ghosh-Choudhury, M.R. Dallas, J. Wozney, and G.R. Mundy. 1995. Recombinant bone morphogenetic protein 2 accelerates bone cell differentiation and stimulates Bmp-2 mRNA expression and BmpP-2 promoter activity in primary fetal rat calvarial osteoblast cultures. Mol. Cell. Differ. 3: 137-155.

Hawley, S.H.B., K. Wunnenberg-Stapleton, C. Hashimoto, M.N. Laurent, T. Watabe, B.W. Blumberg, and K.W.Y. Cho. 1995. Disruption of BMP signals in embryonic Xenopus ectoderm leads to direct neural induction. Genes \& Dev. 9:29232935 .

Hazama, M., A. Aono, N. Ueno, and Y. Fujisawa. 1995. Efficient expression of a heterodimer of bone morphogenetic protein subunits using a baculovinus expression system. Biochem. Biophys. Res. Commun 209: 859-866.

Held, L.I. 1995. Axes, boundaries and coordinates: The ABCs of fly leg development. BioEssays 17: 721-732.

Hemmati-Brivanlou, A. and D.A. Melton. 1992. A truncated 
activin receptor inhibits mesoderm induction and formation of axial structures in Xenopus embryos. Nature 359: 609-614.

Hemmati-Brivanlou, A., O.G. Kelly, and D.A. Melton. 1994. Follistatin, an antagonist of activin, is expressed in the Spemann organizer and displays direct neuralizing activity. Cell 77: 283-295.

Hogan, B.L.M. 1995. Upside-down ideas vindicated. Nature 376: $210-211$.

Holley, S.A., P.D. Jackson, Y. Sasai, B. Lu, E.M. De Robertis, F.M. Hoffmann, and E.L. Ferguson. 1995. A conserved system for dorsal-ventral patterning in insects and vertebrate involving sog and chordin. Nature 376: 249-253.

Huang, H.-C., L.C. Murtaugh, P.D. Vize, and M. Whitman. 1995. Identification of a potential regulator of early transcriptional responses to mesoderm inducers in the frog embryo. EMBO /. 14: 5965-5973.

Hui, C.-C., D. Slusarski, K.A. Platt, R. Holmgreen, and A.L. Joyner. 1994. Expression of three mouse homologs of the Drosophila segment polarity gene cubitus intcrruptus, Gli, Gli-2 and Gli-3, in ectoderm-and mesoderm-derived tissues suggests multiple roles during postimplantation development. Dev. Biol. 162: 402-413.

Ingham, P.W. 1995. Signaling by hedgehog family proteins in Drosophila and vertebrate development. Curr. Biol 5: 492498.

Johansson, B.M. and M.V. Wiles. 1995. Evidence for involvement of activin $A$ and Bone Morphogenetic Protein 4 in mammalian mesoderm and haematopoietic development. Mol. Cell. Biol. 15: 14l-151.

Johnson, R., E. Laufer, R.D. Riddle, and C. Tabin. 1994a. Ectopic expression of Sonic hedgehog alters dorsal-ventral patterning of somites. Cell 79: 1165-1173.

Johnson, R.L., R.D. Riddle, and C.J. Tabin. 1994b. Mechanisms of limb patterning. Curr. Opin. Genet. Dev. 4: 535-542.

Johnson, R.L., J.K. Grenier, and M.P. Scott. 1995. patched overexpression alters wing disc size and pattern: Transcriptional and post-transcriptional effects on hedgehog targets. Devel. opment 121: 4161-4170.

Jones, C.M., K.M. Lyons, and B.L.M. Hogan. 1991. Involvement of Bone Morphogenetic protein $-4(B \mathrm{mp}-4)$ and $\mathrm{Vgr}-1$ in morphogenesis and neurogenesis in the mouse. Development 111: $531-542$.

Jones, C.M., K.M. Lyons, P.M. Lapan, C.V.E. Wright, and B.L.M. Hogan. 1992. DVR-4 (Bone Morphogenetic Protein-4) as a posterior-ventralizing factor in Xenopus mesoderm induction. Development 115: 639-647.

Jones, C.M., M.R. Kuehn, B.L.M. Hogan, J.C. Smith, and C.V.E. Wright. 1995. Nodal-related signals induce axial mesoderm and dorsalize mesoderm during gastrulation. Development 121: $3651-3662$

Jones, C.M., L. Dale, B.L.M. Hogan, C.V.E. Wright, and I.C. Smith. 1996. Bone morphogenetic protein-4 $(B \mathrm{mp}-4)$ acts during gastrula stages to cause ventralization of Xenopus embryos. Development 122: 1545-1554

Katagiri, T., A. Yamaguchi, M. Komaki, E. Abc, N. Takahashi, T. Ikeda, V. Rosen, J.M. Wosney, A. Fujisawa-Sehara, and T. Suda. 1994. Bone morphogenetic protein-2 converts the differentiation pathway of $\mathrm{C} 2 \mathrm{Cl} 2$ myoblasts into the osteoblast lineage. 7 . Cell Biol. 127: 1755-1766.

Kessler, E., K. Takahara, L. Biniaminov, M. Brusel, and D.S. Greenspan. 1996, Bone morphogenetic protein-1: The Type 1 procollagen C-proteinase. Science 271:360-362.

King, J., P.C. Marker, K.S. Seung, and D.M. Kingsley. 1994. Bmp5 and the molecular, skeletal, and soft-tissue alterations in short ear mice. Dev. Biol. 166: 112-122.

Kingsley, D.M. 1994a. The Tgf- $\beta$ superfamily: New members, new receptors, and new genetic tests of function in different organisms. Genes \& Dev. 8: 13.3-146.

1994b. What do BMPs do in mammals? Clues from the mouse short-ear mutation. Trends Genet. 10: 16-22.

Kingslcy, D.M., A.E. Bland, J.M. Grubber, P.C. Marker, L.B. Russel], N.G. Copeland, and N.A. Jenkins. 1992. The mouse short ear skeletal morphogenesis locus is associated with defects in a bone morphogenetic member of the $\mathrm{Tgf} \beta$ superfamily. Cell 71: 399-410.

Koster, M., S. Plessow, I.H. Clement, A. Lorenz, H. Tiedemann, and W. Knockel. 1991. Bone morphogenetic protein 4 (BMP4 , a member of the TGF. $\beta$ family, in early embryos of Xenopus laevis: Analysis of mesoderm inducing activity. Mech. Dev. 33: 191-200.

Lamb, T.M., A.K. Knecht, W.C. Smith, S.E. Stachel, A.N. Economides, N. Stahl, G.D. Yancopolous, and R.M. Harland. 1993. Neural induction by the secreted polypeptide noggin. Sclence 262: 713-718.

Laufer, E., C.E. Nelson, R.L. Johnson, B.A. Morgan, and C. Tabin. 1994. Sonic hedgehog and Fgf.4 act through a signaling cascade and feedback loop to integrate growth and patterning of the developing limb bud. Cell 79: 993-1003.

Lemaire, P., N. Garrett, and J.B. Gurdon. 1995. Expression cloning of Siamois, a Xenopus homeobox gene expressed in dorsal-vegetal cells of blastulate and able to induce a complete secondary axis. Cell 81: 85-94.

Lepage, T., S.M. Cohen, F.J. Diaz-Benjumea, and S.M. Parkhurst. 1995. Signal transduction by cAMP-dependent protein kinase A in Drosophila limb patterning. Nature 373: 711-715.

Levin, M., R.L. Johnson, C.D. Stern, M. Kuehn, and C. Tabin. 1995. A molecular pathway determining left-right asymmetry in chick embryogenesis. Cell 82: 80.3-814.

Lıem, I.K.F., G. Tremml, H. Roelink, and T.M. Jessell. 1995. Dorsal differentiation of neural plate celis induced by Bmpmediated signals from epidermal ectoderm. Cell 82: 969 979.

Liu, F., F. Ventura, J. Doody, and I. Massague. 1995. Human Type II receptor for bone morphogenetic proteins (BMPs;: Extension of the two-kinase receptor model to the BMPs. Mol. Ceil. Biol. 15: 3479-3486

Lumsden, A and A. Graham. 1995. A forward role for Hedgehog. Curr. Biol 5: 1347-1350.

Luo, G., C. Hofmann, A.L.J.J. Bronckers, M. Sohocki, A. Bradley, and G. Karsenty. 1995. Bmp-7 is an inducer of nephrogenesis, and is also required for eye development and skeletal patterning. Genes \& Dev. 9: 2808-2820.

Lyons, K.M., B.L.M. Hogan, and E.J. Robertson. 1995. Colocalization of $B m p 7$ and Bmp 2 RNAs suggest that these factors cooperatively mediate tissue interactions durng murine development. Mech. Dev. 50: $71-8.3$.

Mac Auley, A., Z. Werb, and P.E. Mirkes. 1993. Characterization of the unusually rapid cell cycles during rat gastrulation. Development 117: 873-883.

Maeno, M., R.C. Ong, A. Suzuki, N. Ueno, and H.F. Kung. 1994. A truncated bone morphogenetic protein 4 receptor alters the fate of ventral mesoderm to dorsal mesoderm: Role of animal pole tissue in the development of ventral mesoderm. Proc. Natl. Acad. Sci. 91: 10260-10264.

Marigo, V., M.P. Scott, R.L. Johnson, L.V. Goodrich, and C.J. Tabin. 1996. Conservation in hedgehog signaling: Induction of a chicken patched homolog by Sonic hedgehog in the developing limb development. Development 122: 1225-1233.

Massague, I. and F. Weis-Garcia. 1996. Serine/threonine kinase receptors: Mediators of Tgf- $\beta$ tamily signals. Cancer Surv. 26: (in press).

Massague, J., L. Attisano, and J.L. Wrana. 1994. The Tgf- $\beta$ fam- 
ily and its composite receptors. Trends Cell Biol. 4: 172-178. Masuhara, K., T. Nakase, S. Susuki, K. Takaoka, M. Matsui, and H.C. Anderson. 1995. Use of monoclonal antibody to detect bone morphogenetic protein-4 (Bmp-4). Bone 16: 91-96.

McDonald, N.Q. and W.A. Hendrickson. 1993. A structural superfamily of growth factors containing a cystine knot motif. Cell 73: 421-424.

McGrath, S.A., A.F. Esquela, and S.-1. Lee. 1995. Oocyte-specific expression of growth/differentiation factor-9. Mol. Endocrinol. 9: 131-136.

McPherron, A.C. and S.-J. Lee. 1996. The transforming growth factor $\beta$ superfamily. In Growth factors in health and dis ease led. D. LeRoith\}, Vol. 1B, pp. 357-393. JAI Press, Inc., Greenwich, CT.

Mishina, Y., A. Susuki, N. Ueno, and R.R. Behringer. 1995. BMPr encodes a type I bone morphogenetic protein receptor that is essential for gastrulation during mouse embryogenesis. Genes \& Dev. 9: 3027-3037.

Moos Jr., M., S. Wang, and M. Krinks. 1995. Anti-dorsalizing morphogenetic protein is a novel Tgf- $\beta$ homolog expressed in the Spemann organizer. Development 121: 4293-4301.

Mori, C., N. Nakamura, S. Kimura, H. Irie, T. Takigawa, and K. Shiota. 1995. Programmed cell death in the interdigital tissue of the fetal mouse limb is apoptosis with DNA fragmentation. Anat. Rec. 242: 103-110.

Munsterberg, A.E., J. Kitajewski, D.A. Bumcrot, A.P. McMahon, and A.B. Lassar. 1995. Combinatorial signaling by Sonic hedgehog and Wnt family members induce myogenic bHLH gene expression in the somite. Genes \& Dev. 9: 2911-2922.

Nakamura, T., K. Takio, Y. Eto, H. Shibai, K. Titani, and H. Sugino. 1990. Activin-binding protein from rat ovary is follistatin. Science 247: 836-838.

Niswander, L. and G.R. Martin. 1993. Fgf-4 and Bmp-2 have opposite effects on limb growth. Nature 361: 68-71.

Ozkaynak, E., P.N.J. Schnegelsberg, D.F. Jin, G.M. Clifford, F.D. Warren, E.A. Drier, and H. Oppermann. 1992. Osteogenic protein-2. I. Biol. Chem. 267: 25220-25227.

Pan, D. and G.M. Rubin. 1995. cAMP-dependent protein kinase and hedgehog act antagonistically in regulating decapentaplegic transcription in Drosophila imaginal discs. Cell 80: $543-552$.

Parr, B.A. and A.P. McMahon. 1995. Dorsalizing signal Wnt-7 required for normal polarity of D-V and A-P axes of mouse limb. Nature 374: 350-353.

Parr, B.A., M.J. Shea, G. Vassileva, and A.P. McMahon. 1993. Mouse Wnt genes exhibit discrete domains of expression in the early embryonic CNS and limb buds. Development 119: 247-261.

Pourquie, O., C.-M. Fan, M. Coltey, E. Hirsinger, Y. Watanabe, C. Breant, P. Francis-West, P. Brickell, M. Tessier-Lavigne, and N.M. Le Douarin. 1996. Lateral and axial signals involved in avian somite patterning: A role for Bmp-4. Cell 84: $461-471$.

Raftery, L.A., V. Twombly, K. Wharton, and W.M. Gelbart. 1995. Genetic screens to identify elements of the decapentaplegic signaling pathway in Drosophila. Genetics 139: 214 254.

Re'em-Kalma, Y., T. Lamb, and D. Frank. 1995. Competition between noggin and bone morphogenetic protein 4 activities may regulate dorsalization during Xenopus development. Proc. Natl. Acad. Sci. 92: 12141-12145.

Riddle, R.D., M. Ensini, C. Nelson, T. Tsuchida, T.M. Jessell, and C. Tabin. 1995. Induction of the LIM homeobox gene $L m \times 1$ by Wnt 7 a establishes dorsoventral pattern in the vertebrate limb. Cell 83: 631-640.

Rissi, M., J. Wittbrodt, E. Delot, M. Naegeli, and F.M. Rose.
1995. Zebrafish Radar: A new member of the Tgf- $\beta$ superfamily defines dorsal regions of the neural plate and the embryonic retina. Mech. Dev. 49: 223-234.

Roberts, D.I., R.L. Johnson, A.C. Burke, C.E. Nelson, B.A. Morgan, and C. Tabin. 1995. Sonic hedgehog is an endodermal signal inducing $B m p-4$ and $H O X$ genes during induction and regionalization of the chick hindgut. Development 121: 3163-3174.

Roelink, H., A. Augsburger, J. Heemskerk, V. Korzh, S. Norlin, R.i. Altaba, Y. Tanabe, M. Placzek, T. Edlund, T.M. Jessell, and J. Dodd. 1994. Floor plate and motor neuron induction by wh-1, a vertebrate homolog of hedgehog expressed by the notochord. Cell 76: 761-775.

Roelink, H., J.A. Porter, C. Chiang, Y. Tanabe, D.T. Chang, P.A. Beachy, and T.M. Jessell. 1995. Floor plate and motor neuron induction by different concentrations of the amino-terminal cleavage product of Sonic hedgehog autoproteolysis. Cell 81: 445-455.

Ruberte, E., T. Marty, D. Nellen, M. Affolter, and K. Basler. 1995. An absolute requirement for both the Type II and Type I receptors, punt and thick veins, for Dpp signaling in vivo. Cell 80: 889-897.

Saharinen, I., I. Taipale, and I. Keski-Oja. 1996. Association of the small latent transforming growth factor $-\beta$ with an eight cysteine repeat of its binding protein LTPD-1. EMBO $/$. 15: $245-253$.

Sampath, T.K., J.C. Maliakal, P.V. Hauschka, W.K. Jones, H. Sasak, R.F. Tucker, K.H. White, J.E. Couchlin, M.M. Ticker, R.H.L. Pang, C. Corbett, E. Ozkaynak, H. Oppermann, and D.C. Rueger. 1992. Recombinant human osteogenic protein-1 (hOp-1) induces new bone formation in vivo with a specific activity comparable with natural bovine osteogenic protein and stimulates osteoblast proliferation and differentiation in vitro. /. Biol. Chem. 267: 20352-20362.

Sanchez-Herrero, E., J.P. Couso, J. Capdevila, and I. Guerrero. 1996. The fu gene discriminates between pathways to control dpp expression in Drosophila imaginal discs. Mech. Dev. 55:159-170.

Sasai, Y., B. Lu, H. Steinbeisser, D. Geissert, L.K. Gont, and E.M. De Robertis. 1994. Xenopus chordin: A novel dorsalizing tactor activating by organizer-specific homeobox genes. Cell 79: $779-790$.

Sasai, Y., B. Lu, H. Steinbeisser, and E.M. De Robertis. 1995. Regulation of neural induction by the Chd and Bmp-4 antagonistic patterning signals in Xenopus. Nature 376: 333337

Satokata, I. and R. Maas. 1994. Msx ] deficient mice exhibit cleft palate and abnormalities of craniofacial and tooth development. Noture Genet. 6: 348-355.

Savage, C., P. Das, A.L. Finelli, S.R. Townsend, C.-Y. Sun, S.E. Baird, and R.W. Padgett. 1996. Caenorhabditis elegans genes sma-2, sma-3, and sma-4 define a conserved family of transforming growth factor $\beta$ pathway components. Proc. Natl. Acad. Sci. 93; 790-794.

Schlunegger, M.P. and M.G. Grutter. 1992. An unusual feature revealed by the crystal structure at 2.2 a resolution of human transforming growth factor- $\beta 2$. Nature 358: 430-4.34.

Schmidt, J.E., A. Suzuki, N. Ueno, and D. Kimelman. 1995. Localized Bmp-4 mediates dorsal/ventral patterning in the early Xenopus embryo. Dev. Biol. 169: 37-50.

Schwyter, D.H., J.-D. Huang, T. Dubnicoff, and A.J. Courey. 1995. The decapentaplegic core promoter region plays an integral role in the spatial control of transcription. Mol. Cell. Biol. 15: 3960-3968.

Shimell, M.J., E.L. Ferguson, S.R. Childs, and M.B. O'Connor. 1991. The Drosophila dorsal-ventral patterning gene tolloid 
is related to human bone morphogenetic protein 1 . Cell 67: $469-481$.

Skelesky, I.J., S.J. Newfeld, L.A. Raftery, E.H. Chartoff, and W.M. Gelbart. 1995. Genetic characterization and cloning of mothers against dpp, a gene required for decapentaplegic function in Drosophila melanogaster. Genetics 139: 13471358.

Slack, J.M.W. 1994. Inducing factors in Xenopus early embryos. Curr. Biol. 4: 116-126.

Smith, W.C. and R.M. Harland. 1992. Expression cloning of noggin, a new dorsalizing factor localized to the Spemann organizer in Xenopus embryos. Cell 70: 829-840.

Smith, W.C., A.K. Knecht, M. Wu, and R.M. Harland. 199.3 Secreted noggin protein mimics the Spemann organizer in dorsalizing Xenopus mesoderm. Nature 361: 547-549.

Smith, W.C., R. McKendry, S. Ribisi, Jr., and R.M. Harland. 1995. A nodal-related gene defines a physical and functional domain within the Spemann organizer. Cell 82: 37-46.

Spence, M.S. and C.A. Erickson. 1996. The dorsal neural tube organizes the dermamyotome and induces axial myocytes in the avian embryo. Development 122: 231-241

Staehling-Hampton, K., A.S. Laughon, and F.M. Hoffmann. 1995. A Drosophila protein related to the human zinc finger transcription factor PRDI/MBPI/HIV-EPI is required for dpp signaling. Development 121:3393-3403.

Steinbeisser, H., A. Fainsod, C. Niehrs, Y. Sasal, and E.M. De Robertis. 1995. The role of $g s c$ and $B m p-4$ in dorsal-ventral patterning of the marginal zone in Xenopus: A loss-of-function study using antisense RNA. EMBO /. 14: 52.30-5243.

Storm, E.E., T.V. Huynh, N.G. Copeland, N.A. Jenkins, D.M. Kingsley, and S.-I. Lee. 1994. Limb alterations in brachypodism mice due to mutations in a new member of the Tgf $\beta$ superfamily. Nature 368: 639-643.

Strutt, D.I., V. Wiersdorff, and M. Mlodzik. 1995. Regulation of furrow progression in the Drosophila eyc by cAMP-dependent protein kinase A. Nature 373: 705-709.

Suzuki, A., R.S. Thies, N. Yamaii, I.J. Song, J.M. Wozncy, K Murakami, and N. Ueno. 1994. A truncated bone morphogenetic protein receptor affects dorsal-ventral patterning in the early Xenopus embryo. Proc. Natl. Acad. Sci. 91: 1025510259.

Suzuki, A., E. Kaneko, J. Maeda, and N. Ueno. 1996. Contribution of bone morphogenetic protein $(\mathrm{Bmp})-7$ to ventral mesoderm formation: Heterodimer of Bmp-4 and -7 is a potent ventralizing factor. Development (in press).

Thies, R.S., M. Bauduy, B.A. Ashton, L. Kurtzberg, I.M. Wozney, and V. Rosen. 1992. Recombinant human bone morphogenetic protein-2 induces osteoblastic differentiation in $W-20$ 17 stromal cells. Endocrinology 130: 1318-1324.

Thomsen, G.H. and D.A. Melton. 1993. Processed Vgl protein is an axial mesoderm inducer in Xenopus. Cell 74: 433-441.

Tickle, C. 1995. Vertebrate limb development. Curr. Biol. 5: $478-484$

Timpl, R. and J.C. Brown. 1996. Supramolecular assembly of basement membranes. BioEssays 18: 123-132.

Vaahtokari, A., T. Abert, J. Jernvall, S. Keranen, and I. Thesleff 1996a. The enamel knot as a signaling center in the developing mouse tooth. Mech. Dev. 54: 39-43.

Vaahtokari, A., T. Aberg, and I. Thesleff. 1996b. Apoptosis in the developing tooth: Association with an embryonic signal. ing center and supression by EGF and FGF. Development 122: $121-129$.

Vainio, S., I. Karavanova, A. Jowett, and I. Thesleff. 1993. Identification of Bmp-4 as a signal mediating sccondary induction between epithelial and mesenchymal tissues during early tooth development. Cell 75: 45-58.
Vukicevic, S., F.P. Luyten, and A.H. Reddi. 1989. Stimulation of the expression of osteogenic and chondrogenic phenotypes in vitro by osteogenin. Proc. Natl. Acad. Sci. 86: 8793-8797.

Wall, N.A., M. Blessing, C.V.E. Wright, and B.L.M. Hogan. 1993. Biosynthesis and in vivo localization of the decapentaplegicVg-related protein, DVR-6 (bonc morphogenetic protein-61.). Cell Biol 120: 49.3-502.

Wharton, K.A., R.P. Ray, and W.M. Gelbart. 1993. An activity gradient of decapentaplegic is necessary for the specification of dorsal pattern elements in the Drosophila embryo. Development 117: 807-822.

Wilson, P.A. and D.A. Melton. 1994. Mesodermal patterning by an inducer gradient depends on secondary cell-cell communication. Curr. Biol. 4: 676-686.

Wilson, P.A. and A. Hemmati-Brivanlou. 1995. Induction of epidermis and inhibition of neural fate by $B \mathrm{mp}-4$. Nature 376: 331-333.

Winnier, (;., M. Blcssing, P.A. Labosky, and B.L.M. Hogan. 1995. Bone morphogenetic protein-4 is required for mesoderm formation and patterning in the mouse. Genes \& Dev. 9: $2105-2116$.

Wozney, I.M., V. Rosen, A. J. Celeste, L.M. Mitsock, M.J. Whitters, R.W. Kris, R.M. Hewick, and E.A. Wang. 1988. Novel regulators of bone formation: Molecular clones and activitics. Science 242: 1528-1534.

Xu, J., K. McKechan, K. Matsuzaki, and W.L. McKechan. 1995. Inhibin antagonizes inhibition of liver cell growth by activin by a dominant-negative mechanism. 1. Biol. Chem, 270: 6.3086.313.

Xu, R.-H., Z. Dong, M. Maeno, J. Kim, A. Suzuki, N. Ueno, D. Sredni, N.H. Colburn, and H.F. Kung. 1996. Involvement of Ras/Raf/Ap-1 in Bmp-4 signaling during Xenopus embryonic development. Proc. Natl. Acad. Sci. 93: 834-8.38.

Yamaii, N. A.I. Celeste, R.S. Thies, I.J. Song, S.M. Bernier, D. Golzman, K.M. Lyons, I. Noe, V. Rosen, and J.M. Wozney. 1994. A mammalian serine/threonine kinase receptor specifically binds Bmp-2 and Bmp-4. Biochem. Biophys. Res. Commun 205: 1944-1951.

Yamaguchi, A., T. Katagiri, T. Ikeda, J.M. Wozney, V. Rosen, E.A. Wang, A.J. Kahn, T. Suda, and S. Yoshiki. 1991. Recombinant human bone morphogenetic protein-2 stimulates ostcoblastic maturation and inhibits myogenic differentiation in vitro. 1. Cell Biol. 113:681-687.

Yamashita, H., P. ten Diike, D. Huylebroeck, T.K. Sampath, M. Andries, I.C. Smith, C.-H. Heldin, and K. Miyazono. 1995. Osteogenic protein-1 binds to activin type II receptors and induces certain activin-like effects. /. Biol. Chem. 130: 217 226

Yang, Y. and L. Niswander. 1995. Interaction between the signaling molecules Wnt $7 \mathrm{a}$ and Shh during vertebrate limb development: Dorsal signals regulate anteroposterior parterning. Cell 80: 939-947.

Zhao, G. $_{3}$ Q Q. and B.L.M. Hogan. 1996. Evidence that Bmp8a|Op2) and $B m p 8 b$ are duplicated genes that play a role in spermatogenesis and placental development. Mech. Dev. (in press).

Zhao, G.-Q., K. Deng, P.A. Labosky, L. Liaw, and B.L.M. Hogan. 1996. The gene encoding bone morphogenetic protein $8 \mathrm{~B}$ [BMP\&B is required for the initiation and maintenance of spermatogenesis in the mousc. Genes \& Dev. 10: |this issue\}.

Zhou, X., H. Sasaki, L. Lowe, B.L.M. Hogan, and M.R. Kuehn. 1993. Nodal is a novel Tgf- $\beta$-like gene expressed in the mouse node during gastrulation. Nature 361: 543-547.

Zou, H. and L. Niswander. 1996. Requirement for BMP signaling in interdigital apoptosis and scale formation. Science 272: $7.38-741$ 


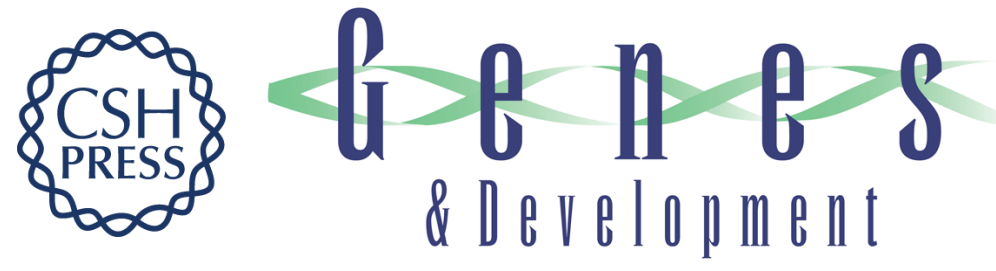

\section{Bone morphogenetic proteins: multifunctional regulators of vertebrate development.}

B L Hogan

Genes Dev. 1996, 10:

Access the most recent version at doi:10.1101/gad.10.13.1580

References This article cites 154 articles, 62 of which can be accessed free at:

http://genesdev.cshlp.org/content/10/13/1580.full.html\#ref-list-1

License

Email Alerting

Service

Receive free email alerts when new articles cite this article - sign up in the box at the top right corner of the article or click here.

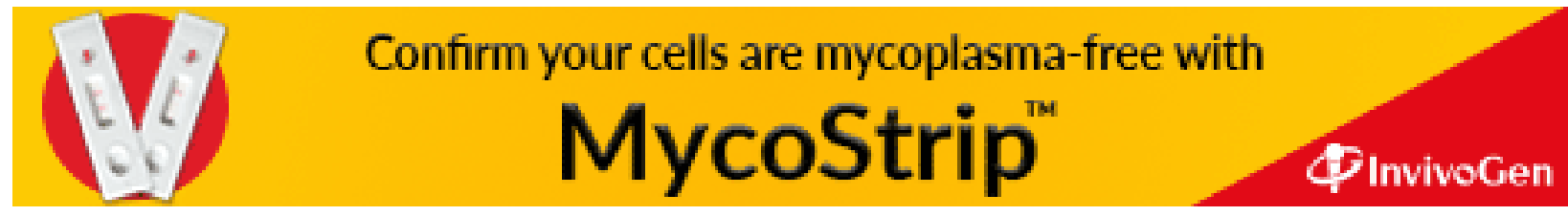

